\title{
Editorial
}

\section{Dolarización: Crónica de una medida dictatorial anunciada}

En la noche del 22 de noviembre, el presidente Francisco Flores sorprendió a la nación en cadena de radio y televisión, al anunciar la puesta en marcha de un "plan de integración monetaria", que, rápidamente, fue interpretado por analistas y por los diversos sectores nacionales como un proceso de dolarización de la economía.

El anuncio no debía sorprender, dado que dicha medida se venía preparando desde hace tiempo, como lo demostraban las políticas monetarias llevadas a cabo por el Banco Central de Reserva. En enero del presente año, el Departamento de Economía de la UCA ya había dicho: "En cuanto a los agregados monetarios, se encuentran indicios claros de una política monetaria restrictiva; además, existe un esfuerzo deliberado por conducir la economía hacia un esquema de caja de convertibilidad o de dolarización." (ECA $\mathrm{N}^{\circ}$ 615-616, pp. 20). Adicionalmente, en su discurso de toma de posesión en junio de 1999, el señor Presidente afirmó que: "Sería impensable de nuestra parte introducir riesgos al régimen cambiario actual. Más aún: debemos eliminar la posibilidad de que un mandatario o Gobierno devalúe arbitrariamente la moneda. De ahí que debamos plasmar y fijar en el ancla segura de nuestras leyes el marco jurídico que imposibilite manipulaciones cambiarias en favor de grupos y de intereses especiales. De esta manera evitaremos que en el futuro se puedan dar devaluaciones arbitrarias, que serían el más cruel atropello contra el ahorro y el patrimonio de los salvadoreños". Pero la sorpresa y la confusión tuvieron su origen en dos movidas que reflejan la astucia política del mandatario; por un lado, se evitó a toda costa utilizar el término de "dolarización", que tanta polémica había ocasionado 
desde su proposición en 1994 bajo la administración de Calderón Sol, y que fue recibido en aquellos momentos con un total rechazo por parte de varios sectores nacionales; $y$, por otro lado, después de las palabras del Presidente en su discurso de toma de posesión no se volvió a tocar oficialmente el tema, indicando que se estaba esperando el momento políticamente propicio para implementar la medida de la forma más rápida posible.

Si bien era necesario definir una política cambiaria que no fuera tan híbrida ni confusa como la que se tenía, el tipo de cambio estaba fijo en la práctica desde 1993, pero el Banco Central añadía a la confusión al sostener injustificadamente que en El Salvador se manejaba un sistema de tipo de cambio flexible, y además se enorgullecía de la estabilidad cambiaria, gastando miles de colones en la propaganda informativa que a diario aparecía, y sigue apareciendo, en los periódicos, indicando el tipo de cambio del día - paradójicamente, éste siempre era el mismo-. Desde este punto de vista, al fin se sabe con certeza lo que el gobierno quería hacer.

Pero es lamentable la forma en que fue aprobada la nueva ley. Para el gobierno, el momento político no fue un momento de consenso con la oposición, ni mucho menos con los sectores sociales, sino que fue la oportunidad que se le presentó de negociar con el PCN el fuero para el diputado Merino a cambio de la aprobación de la "Ley de Integración Monetaria". En otras palabras, aunque ya es un hecho consumado, eso no quita que la nueva ley nació manchada al haberse vendido a cambio de la impunidad del diputado Merino. Así, no se comprende cómo, en palabras del mismo Presidente de la República, se quiere fijar el tipo de cambio con el ancla segura de nuestras leyes, cuando él y su mismo partido llevaron a cabo una sucia negociación política con el PCN, demostrando a toda la población que en nuestro país las leyes no son ninguna ancla segura.

Una reforma monetaria-cambiaria importantísima se ha llevado a cabo en el país, con poca participación o escasa influencia de la Deshonrada Asamblea Legislativa. Concomitante a la aprobación de una medida trascendental, se da el rechazo por parte de la Asamblea de retirar el fuero parlamentario al diputado Merino - sin los votos del FMLN y el CDU-, que, estando borracho, atacó a balazos a una policía y un policía; el argumento de un notable diputado de ARENA: no hay víctimas, los daños ya fueros resarcidos. De allí que vale la pena repetir: la aprobación de una medida trascendental se dio con poca participación, y ninguna influencia de la Deshonrada Asamblea Legislativa. Oculto bajo la formalidad de la aprobación de un decreto, independientemente de su validez constitucional, se encuentran oscuras negociaciones entre el Ejecutivo, el partido gobernante, ARENA, y el partido taxi, el PCN. Dolarización a cambio de protección. 
Es más, con este tipo de atropellos a la legislación del país —más un sinnúmero de violaciones adicionales que harían interminable este editorial一, se evidencia, cada día con mayor claridad, que el gobierno actual tiene al menos una de las características de un régimen dictatorial: la emancipación del poder respecto de los frenos y de los controles normales. En el diccionario de política de Norberto Bobbio y Nicola Matteucci se afirma lo siguiente: "El gobierno dictatorial no está frenado por la ley, está por encima de ella y traduce en ley su propia voluntad. Aun cuando son mantenidas o introducidas normas que salvaguardan nominalmente los derechos de libertad, o limitan en cambio el poder del gobierno, estas reglas jurídicas son un velo exterior, con escasa o ninguna eficacia real, que el gobierno dictatorial puede desobedecer con discreción más o menos absoluta, recurriendo a otras leyes que contradicen a las primeras o hacen excepción de ellas, utilizando potentes organismos políticos sustraídos al derecho común, o invocando directamente los pretendidos principios superiores que guían la acción del gobierno y prevalecen sobre cualquier ley". (Bobbio, pp. 558) Se presenta esta cita porque, además del sucio trato antes mencionado, la nueva ley adolece de problemas con la Constitución.

Ahora bien, siendo un hecho ya consumado, la millonaria propaganda realizada por el gobiemo acerca de los beneficios de la medida es un absurdo total, pues según ellos, en un principio sólo habrá beneficios: no se menciona ningún costo. En la presentación oficial de la nueva medida económica se mencionan únicamente seis ventajas: mejores condiciones financieras, un sistema monetario más competitivo y sano, salarios y ahorros más seguros, mayor estabilidad para la inversión, y un nivel más amplio de estabilidad política. Pero se mantiene un silencio absoluto con respecto a las desventajas, tales como la carencia de una política monetaria con fines de estabilización económica, la pérdida por intereses más bajos para los depositantes, desaparición del Banco Central como prestamista de última instancia en caso de crisis financieras, el aumento de la deuda pública y, por tanto, mayor presión sobre el déficit fiscal. En caso de shocks, el ajuste real de la economía se dará por vía de reducción en el empleo o por la vía de reducción de los salarios. Teniendo a mano tanto la lista de los beneficios como la de los costos, el balance ya no puede ser tan optimista como el discurso gubernamental.

Es de lamentar, sin embargo, que si se toma en cuenta el momento del ciclo económico, en que viene un incremento de las exportaciones de maquila por la expansión de la ICC, y si prosigue, un aumento de la inversión pública con el Plan de Nación, y un entorno de crecimiento más favorable en América Latina, entonces los efectos negativos de la dolarización se van a ver menguados. De allí que es posible que no se perciba mucha oposición o arrepentimiento por la medida en el futuro.

Una vez tomada la decisión, la ejecución de esta medida trascendental es algo relativamente sencillo, no así los cambios verdaderos que requiere el país 
para poder insertarse exitosamente en el proceso de globalización, y mucho más importante, para encaminarse a un proceso de desarrollo humano que ataque frontalmente los problemas de la pobreza injustificada e injusta, como son: la solución a los problemas de las finanzas públicas, aumentando la recaudación tributaria, y volviendo a asignar el presupuesto, según criterios de equidad y eficiencia; la creación y rehabilitación de instituciones; más transparencia y menos corrupción; incrementos en la productividad, —la única vía para crecer-; una política social seria que erradique en cinco años la pobreza extrema; y la promoción de valores como el respeto, la honestidad, la honradez, el trabajo, la excelencia, etc. Esto ha quedado evidenciado con la experiencia de la caja de convertibilidad aplicada en Argentina. En el país sudamericano se estuvo casi diez años bajo ese esquema, y los problemas estructurales en sus finanzas públicas y en el sistema financiero aún no han sido resueltos, como lo demuestra la crisis actual, en que se ha tenido que recurrir a una apoyo de veinte mil millones de dólares por parte del FMI.

En contraste con la facilidad con que se adoptó la dolarización, la entrada en vigencia de reformas institucionales y de reformas para reducción de la pobreza, implícitamente presentes en los cambios necesarios mencionados anteriormente, generalmente requieren o pasan por los intereses de sectores o grupos económicos poderosos que no estarán a favor de tales cambios, menos aún si tienen tendencias dictatoriales. Después que pase la sorpresa y que nos acostumbremos al uso de los billetes verdes, irá quedando claro en el pueblo que los problemas fundamentales del país no han cambiado, y que por tanto la lucha legítima por una sociedad más justa y próspera debe continuar, y tal vez, se le cobre la factura al gobierno en las próximas elecciones. 